Provided for non-commercial research and education use. Not for reproduction, distribution or commercial use.

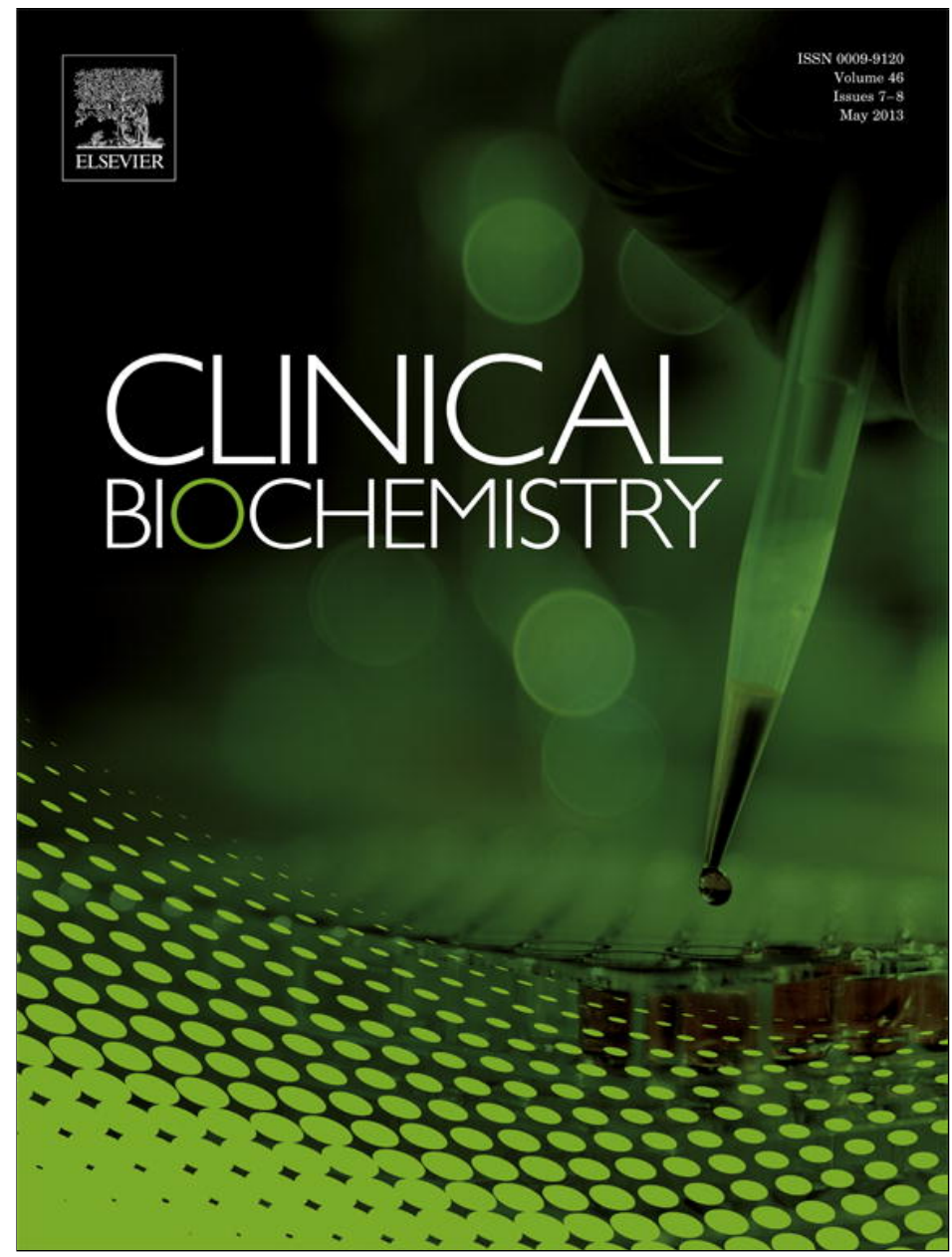

This article appeared in a journal published by Elsevier. The attached copy is furnished to the author for internal non-commercial research and education use, including for instruction at the authors institution and sharing with colleagues.

Other uses, including reproduction and distribution, or selling or licensing copies, or posting to personal, institutional or third party websites are prohibited.

In most cases authors are permitted to post their version of the article (e.g. in Word or Tex form) to their personal website or institutional repository. Authors requiring further information regarding Elsevier's archiving and manuscript policies are encouraged to visit:

http://www.elsevier.com/authorsrights 


\title{
Rapid, sensitive and simultaneous determination of ascorbic and uric acids in human plasma by ion-exclusion HPLC-UV
}

\author{
Rita Ferin ${ }^{\mathrm{a}, \mathrm{b}, *}$, Maria Leonor Pavão ${ }^{\mathrm{a}, \mathrm{b}}$, José Baptista ${ }^{\mathrm{a}, \mathrm{b}}$ \\ a Department of Technological Sciences and Development, University of the Azores, Rua da Mãe de Deus, 9501-801 Ponta Delgada, Azores, Portugal \\ ${ }^{\mathrm{b}}$ Center of Research in Natural Resources (CIRN), University of the Azores, Rua da Mãe de Deus, 9501-801 Ponta Delgada, Azores, Portugal
}

\section{A R T I C L E I N F O}

\section{Article history:}

Received 7 August 2012

Received in revised form 20 December 2012

Accepted 13 January 2013

Available online 23 January 2013

\section{Keywords:}

Ascorbic acid

Uric acid

Plasma antioxidants

HPLC-UV

Ion-exclusion

Atherosclerosis

\section{A B S T R A C T}

Objectives: Ascorbic (AA) and uric (UA) acids act as antioxidants and are capable to react with biologically relevant oxidants. We aimed to developed a simple, rapid, sensitive, and accurate ion-exclusion HPLC-UV methodology for the simultaneously determination of AA and UA in human plasma.

Methods: Analytical pre-requisites, such as the use of heparin as an anticoagulant and meta-phosphoric acid as a stabilizer were added for accurate and reliable measurements.

Chromatographic separation was achieved by an isocratic elution on a HEMA-BIO 1000 SB analytical column using a phosphate buffer, $\mathrm{pH} 2.4$, as a mobile phase.

Results: Results indicated an excellent linearity with correlation coefficients $\left(r^{2}\right) \geq 0.999$. The LOD of AA and UA was 1.02 and $1.42 \mathrm{nmol} / \mathrm{mL}$, respectively, while LOQ ranged from 0.306 to $0.426 \mathrm{nmol} / \mathrm{mL}$. A great repeatability for both antioxidants was found, where the CV (\%) values for intra-day were lower than $1.8 \%$ and under $6.5 \%$ for the inter-day assay. The recovery of AA ranged from $92 \%$ to $96 \%$ and from $99 \%$ to $100 \%$ for UA.

Conclusion: This validated method allows the determination of both antioxidants within 10 min, and is well suited to routine measurements and/or high-throughput clinical analysis. The methodology was applied to assess the antioxidant status of a group of Azorean subjects.

(C) 2013 The Canadian Society of Clinical Chemists. Published by Elsevier Inc. All rights reserved.

\section{Introduction}

Atherosclerosis (AT), hardening and narrowing of the arteries, is the major cause of cardiovascular disease (CVD), and is a multifactor progressive pathological process where inflammation and oxidative processes have a central role, from fatty streak formation to plaque rupture and thrombosis [1]. Several studies suggested that the oxidation of low-density lipoprotein (LDL)-cholesterol may play an important role in promoting premature AT. According to the oxidativemodification hypothesis of atherogenesis, LDL-cholesterol in its native state is not atherogenic. However, LDL-cholesterol particles will become atherogenic and initiate the atherosclerotic silent process, with the formation of foam cells, if they are oxidatively modified [2]. The antioxidant content of LDL-cholesterol is critical for its protection. As a result, the balance between the pro-oxidant challenge and the presence of antioxidants determines the extent of the arterial wall modification $[3,4]$. Antioxidants such as ascorbic acid (AA) and uric acid (UA) (Fig. 1)

\footnotetext{
* Corresponding author at: Department of Technological Sciences and Development, University of the Azores, Apartado 1422, 9501-801 Ponta Delgada, Azores, Portugal. Fax: + 351296650171 .

E-mail addresses: rborges@uac.pt (R. Ferin), lpavao@uac.pt (M.L. Pavão), baptista@uac.pt (J. Baptista).
}

participate in defense mechanisms against oxidative damage as free radical scavengers [5].

L-Ascorbic acid (vitamin C) is a water-soluble vitamin which is involved in several biochemical reactions in cells and tissues [6]. Under physiological conditions, AA is an electron donor, which allows it to react with biologically relevant radicals and other oxidants such as superoxide anion, hydroxyl radical, singlet oxygen and hypochlorous acid [7]. Furthermore, it can regenerate vitamin E ( $\alpha$-tocopherol) from both $\alpha$-tocopheryl radical and tocophrylquinone in membranes [7]. Vitamin $C$ also acts as a cofactor for enzymes involved in the biosynthesis of collagen and carnitine, participates in the conversion of neurotransmitter dopamine to norepinephrine and in the metabolism of tyrosine [8], and is involved in the absorption of iron from non-heme sources from intestine [6]. Almost all animals are able to endogenously synthesize large quantities of vitamin C. However, humans lost this ability as a result of a series of inactivating mutations of the gene encoding gulonolactone oxidase (GULO), the rate limiting enzyme in the vitamin $\mathrm{C}$ biosynthetic pathway. Therefore, to compensate, humans must consume exogenous vitamin $C$ on a daily basis, from a variety of dietary sources as fruit and vegetables $[7,9,10]$.

UA is the end product of endogenous and dietary purine nucleotide metabolism in humans. It is derived from xanthine, which, in turn, results from hypoxanthine, being both reactions catalyzed by xanthine oxidase $[11,12]$. In most species, UA is further metabolized 
a)<smiles>O=C1OC(C(O)CO)C(O)=C1O</smiles>

$+2 \mathrm{H}$<smiles>O=C1OC(C(O)CO)C(=O)C1=O</smiles><smiles>O=C1OC(C(O)CO)C(=O)C1=O</smiles>

Dehydroascorbic acid

Ascorbic acid

b)<smiles>O=C1NC(=O)C2NC(=O)NC2N1</smiles>

\section{Uric Acid}

Fig. 1. Chemical structures: a) oxidation and reduction of ascorbic acid and b) uric acid.

to allantoin by the urate oxidase (uricase) enzyme, but humans lack this enzyme because of a defective gene that is not transcribed $[13,14]$. Therefore, UA is excreted in urine, and plasma UA levels in humans are appreciably higher as compared to those in most mammals. Studies in vitro have pointed out the important role of uric acid as an antioxidant substance, acting as a potent scavenger of singlet oxygen and hydroxyl radicals and as a chelator of transitional metal ions which are thus converted to poorly reactive forms [12,15].

Several methods have been presented by different researchers for the determination of ascorbic and uric acids in biological samples such as: spectrophotometric methods, high performance liquid chromatography (HPLC) with electrochemical (EC) or ultraviolet (UV) detection $[16,17]$, and capillary electrophoresis (CE) coupled with UV [18] or EC [19]. However, only a few studies have described the simultaneous determination of AA and UA. Several pre-analytical procedures are required for an accurate and reliable determination of these two antioxidants in human plasma, mainly because AA is extremely sensitive to oxidation and degradation during blood sampling, handling, storage, and analysis $[20,21]$. Additionally, it is necessary to stabilize the plasma samples by protecting them from light and high temperatures, as well as acidifying the samples before storage, particularly when it is not possible to immediately perform the analysis. According to Lykkesfeldt [22] the blood collection, including the anticoagulant used, have considerable influence on the outcome data.

The aim of the present study was the development of a simple, rapid, sensitive, precise, and accurate ion-exclusion HPLC-UV methodology (isocratic elution) for the simultaneously determination of AA and UA to be applied to blood samples donated by Azorean subjects with no declared chronic diseases.

\section{Materials and methods}

\section{Chemicals}

$\mathrm{L}(+)$-Ascorbic acid, dehydro-L-ascorbic acid (DHAA), perchloric acid (PCA), and acetonitrile were purchased from Sigma-Aldrich (Sigma-Aldrich Chemie, Steinheim, Germany). Meta-phosphoric acid (MPA), trichloroacetic acid (TCA), sodium dihydrogen phosphate $\left(\mathrm{NaH}_{2} \mathrm{PO}_{4}\right)$, and dodecyltrimethyl ammonium chloride were obtained from Fluka (Sigma-Aldrich Chemie, Steinheim, Germany). Potassium dihydrogeno phosphate $\left(\mathrm{KH}_{2} \mathrm{PO}_{4}\right)$, uric acid, and ortho-phosphoric acid were provided by Merck (Darmstadt, Germany). Sodium hydroxide $(\mathrm{NaOH})$ and ethylenediaminetetraacetic acid disodium $\left(\mathrm{Na}_{2} \mathrm{EDTA}\right)$ were obtained from Riedel-de Haën (Sigma-Aldrich Chemie, Steinheim, Germany). Deionized water obtained from an in-house Milli-Q water purification system (Millipore, Bedford, MA, USA) was used for the preparation of the mobile phase and the standard solutions. All solvents were HPLC grade and standards of the highest purity available.

\section{Blood samples}

Stability is a key problem of AA blood analysis, because AA is rapidly degraded to DHAA (Fig. 1). Both AA oxidation and DHAA hydrolysis are further prevented to some extent by acidification. Acids as PCA, TCA, and MPA have been investigated for the AA stabilization [23,24]. However, MPA showed to be more efficient, considering both stabilization of AA and DHAA and precipitation of plasma sample proteins. MPA was adopted in our study because it also showed the ability to separate from AA with superior resolution and left lower level of contamination.

Whole blood samples were collected from 321 (187 women and 134 men) subjects (under fasting conditions) whom consented to participate in this study. Venous blood was drawn in heparinised vacutainers Sarstedt (Sarstedt AG \& Co., Nümbrecht, Germany) by a standardized procedure of venipucture. The individuals were selected under the following criteria: apparently healthy with no declared chronic diseases (including diabetes and CVD), aged 20 to 60 years, all born and living in the Azores Archipelago (Portugal). Subjects that had been taking vitamin supplements were excluded from the study. The study received ethical committee approval of our institution and all participants provided written informed consent.

Plasma was generated by immediately centrifugation at $2500 \times \mathrm{g}$ for $15 \mathrm{~min}$ at $4{ }^{\circ} \mathrm{C}$. One aliquot of plasma in an opaque Eppendorf tube was exhaustively vortexed with cold freshly prepared $10 \%$ MPA (1:1; v/v) for $30 \mathrm{~s}$, and stored at $-80{ }^{\circ} \mathrm{C}$ until further analysis. For the quantification of the analytes, thawed plasma samples were vortexed and then centrifuged at $16,000 \times g$ for $15 \mathrm{~min}$ at $4{ }^{\circ} \mathrm{C}$. One aliquot of $20 \mu \mathrm{L}$ from the clear supernatant was promptly used for chromatographic analysis. All the procedures were performed under light protection. 


\section{Standards preparation and calibration curves}

A standard stock solution containing $5 \mathrm{mmol} / \mathrm{L}$ of AA was freshly, daily prepared in Milli-Q water. The working standard solutions of AA were prepared by diluting the stock solution with Milli-Q water, covering the range of $0-200(0,5,15,25,50,75,100,150,200) \mu \mathrm{mol} / \mathrm{L}$ analyzing each working standard solution in quadruplicate. The stock solution of UA was freshly prepared at $1.2 \mathrm{mmol} / \mathrm{L}$ by dissolving in $20 \mathrm{mmol} / \mathrm{L} \mathrm{NaOH}$. The working standard solutions of UA ranged from 0 to $500(0,10,30,60,120,200,300,400,500) \mu \mathrm{mol} / \mathrm{L}$, and were prepared by appropriately diluted stock solution with $20 \mathrm{mmol} / \mathrm{L} \mathrm{NaOH}$. All daily prepared stock and working standard solutions were carefully protected from light during preparation and analyses, and were also maintained in ice. The multicalibration curves were constructed by plotting the peak area of each analyte against concentration which gave the values of the slope along with the intercept and correlation coefficient for each calibration curve.

\section{Chromatographic conditions}

Plasma sample analyses were carried out with an Agilent Technologies (Avondale, PA, USA) HPLC model 1200 system with UV (DAD) detector. Two different types of reversed phase columns, with different degrees of hydrophobicity and different carbon loadings were initially tested for the MPA, AA and UA separation from the other plasma components. The separation was investigated, for the best resolution, using mobile phases with different ratios of organic phase to aqueous phase and different $\mathrm{pH}$ values. In order to achieve a complete separation, particularly between MPA and AA, a fine-tuning resolution was performed with Chromolith Performance RP18-5 $\mu \mathrm{m}(100 \mathrm{~mm} \times 4.6 \mathrm{~mm}$ I.D. $)$ column coupled with a Chromolith Performance RP18-5 $\mu \mathrm{m}(10 \mathrm{~mm} \times 4.6 \mathrm{~mm})$ guard column, provided by Phenomenex (Torrence, CA, USA), following the methodology of Karlsen et al. [25] with slightly modification. The mobile phase was prepared by addition of $2 \%$ acetonitrile to the aqueous phase $\left(2.5 \mathrm{mmol} / \mathrm{L} \mathrm{NaH} \mathrm{PO}_{4}, 2.5 \mathrm{mmol} / \mathrm{L}\right.$ dodecyltrimethyl ammonium chloride and $1.25 \mathrm{mmol} / \mathrm{L} \mathrm{Na} \mathrm{EDDT}_{2}$ in milli-Q water). The flow rate was $0.6 \mathrm{~mL} / \mathrm{min}$. The injection volume used was $5 \mu \mathrm{L}$. A variable wavelength DAD detector was used at $264 \mathrm{~nm}$. The results of these experiments have shown a partially overlapped MPA and AA signals that compromise the quantification accuracy. In order to improve the separation the present method was developed using an HEMA-BIO 1000 SB analytical column $(250 \times 4.6 \mathrm{~mm}$ I.D., $10 \mu \mathrm{m}$ particle size; obtained from Tessek, Ltd., Prague, Czech Republic) protected by a Onyx Monolithic C18 guard-column $(10 \times 4.6 \mathrm{~mm}$, I.D.; provided by Phenomenex, Torrence, CA, USA). The mobile phase consisted of $20 \mathrm{mmol} / \mathrm{L} \mathrm{KH}_{2} \mathrm{PO}_{4}$, $\mathrm{pH} 2.4$, after filtration through a $0.45 \mu \mathrm{m}$ cellulose acetate membrane Whatman (Dassel, Germany). The temperature of the column oven was maintained at $35{ }^{\circ} \mathrm{C}$, and the flow rate used was $0.50 \mathrm{~mL} / \mathrm{min}$. An aliquot of $20 \mu \mathrm{L}$ was injected through a Rheodyne 71251 injection valve fitted with a $20 \mu \mathrm{L}$ sample loop (Rheodyne, Cotati, CA, USA). For UV-detection the wavelength (DAD) was set at $245 \mathrm{~nm}$. The quantitative determinations were achieved by using the external standard method with the Agilent Technologies ChemStation software and working standard solutions of the analytes. The sample concentration was limited to the linearity range in order to avoid peak tailing and retention time shifting, which may occur when the sample amount approaches the column sample load capacity. Results were expressed as $\mu \mathrm{mol} / \mathrm{mL}$ of plasma and all analysis were performed in triplicate. The chromatograms were recorded according to the retention time.

\section{Method validation}

The analytical method was validated taking into consideration the precision, repeatability, specificity, sensitivity, linearity within the referred concentration ranges, and recovery [26].
The precision of the chromatographic methodology was evaluated by performing intra- and inter-day multiple injections of AA and UA standard solutions with three different concentrations, and by checking the percentages of the coefficient of variation of the peak area. The specificity of the method was tested by co-elution of AA and UA with authentic standards and by spectral comparison with standards using the diode-array detector. The sensitivity of the method was determined by quantifying the limit of detection (LOD) that was evaluated using a lower analyte concentration that would yield a signal-to-noise ratio $(\mathrm{S} / \mathrm{N})$ of 3 ; the limit of quantification (LOQ) represents the analyte concentration that would yield a signal-to-noise $(\mathrm{S} / \mathrm{N})$ of 10 . The linearity of the method was investigated with the use of AA and UA calibration curves from freshly standard solutions within the expected and exceeding concentration ranges. The accuracy of this method was evaluated by determining the recovery of AA and UA in samples with known amounts of these two antioxidants. Three different known amounts of each standard compound were added to the plasma sample which was subjected to the HPLC chromatographic analysis. The recovery was calculated based on the difference between the total concentration determined in the spiked samples and the concentration observed in the non-spiked samples. All analyses were carried out in triplicate.

\section{Statistical analysis}

Statistical analysis was performed by using SPSS 15.0 for software for windows (SPSS Institute, Chicago, IL). Linear regression was applied to develop an equation to predict the AA and UA plasma concentrations. Differences between men and women were tested by Student's $t$-test and data are presented as mean \pm SD. A P-value of $<0.05$ was considered to be statistically significant.

\section{Results and discussion}

\section{Sample preparation}

For a reliable and correct chromatographic separation of AA and UA from plasma, it is required to take pre-analytical procedures since stability is a crucial problem for these antioxidants. The whole blood samples must be collected into vacutainer tubes containing heparin as anticoagulant $[25,27,28]$, and must be kept in the dark and at $+4{ }^{\circ} \mathrm{C}$ until plasma was separated from cells, since temperature, light, and the presence or absence of oxygen induces the analytes' degradation [29]. Immediately after the centrifugation, plasma samples were acidified with meta-phosphoric acid to stabilize the sample before storage at $-80{ }^{\circ} \mathrm{C}$ since measurements could be performed within this time [27].

\section{Chromatographic separation}

A representative HPLC chromatogram of the human plasma sample obtained is shown in Fig. 2. Retention times for AA and UA were $6.056 \mathrm{~min}$ and $8.463 \mathrm{~min}$, respectively. The identification of the peaks was done by comparison of the retention times with those corresponding to the pure standards ran separately in the same analytical conditions, confirmed by spike of the authentic standards to the plasma sample and by spectral comparison with standards using the DAD profile between 200 and $400 \mathrm{~nm}$. The isocratic elution of the two analytes was completed within 10 min (Fig. 2), allowing a new injection every 12 min and consequently a high-throughput HPLC analyses. The complete chromatographic separation of the three analytes (MPA, AA and UA), particularly between MPA and AA, was successfully achieved using the HEMA-BIO 1000 SB, a strong cation exchange analytical column containing sulphobuthly groups. These groups are bound to a hydrophilic hydroxyethyl methacrylate backbone. The retention on the ion-exchange columns is controlled by electrostatic attraction and/or repulsion forces, hydrophobic interactions and the size-exclusion effect 


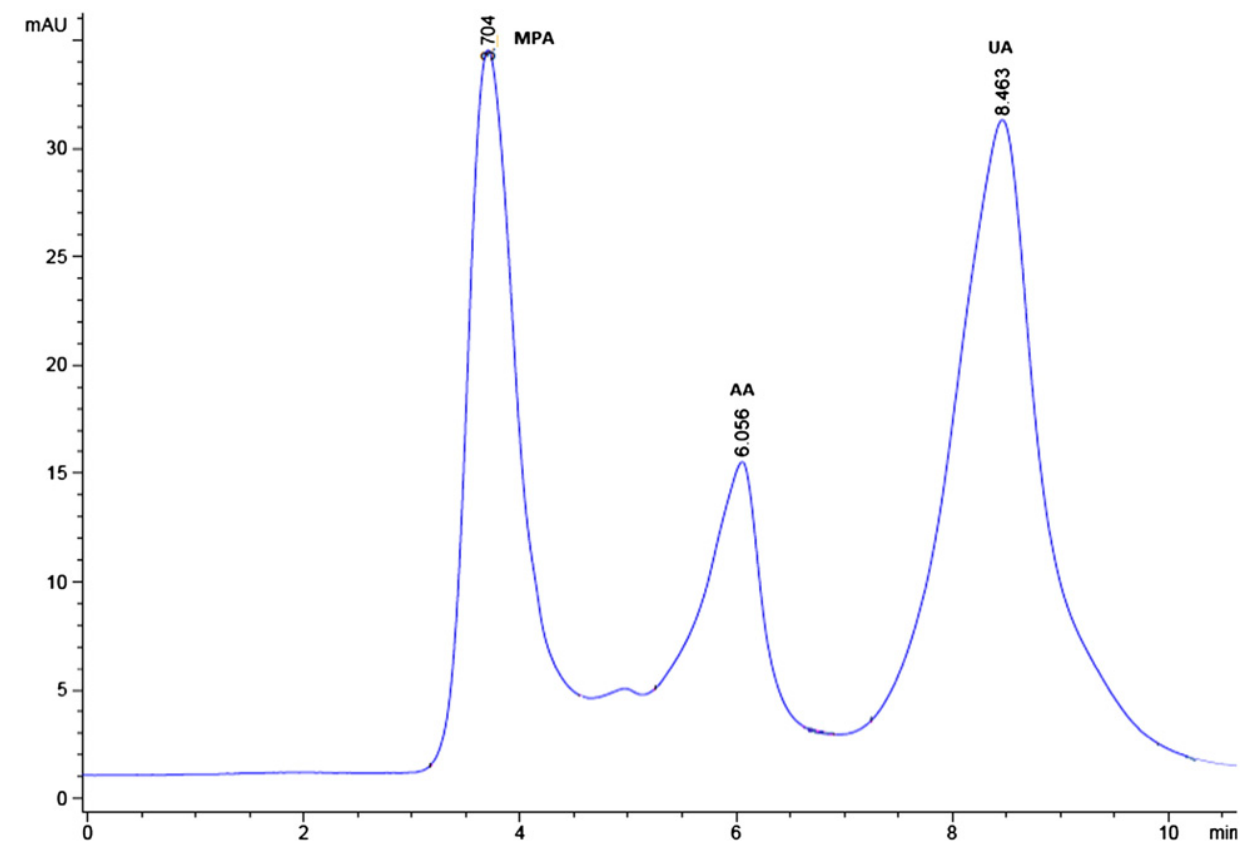

Fig. 2. HPLC chromatogram obtained from the analysis of plasma sample with UV detection. Chromatographic conditions: HEMA-BIO 1000 SB column $(250 \times 4.6$ mm I.D., $10 \mu \mathrm{m})$; Mobile phase: isocratic elution with $20 \mathrm{mmol} / \mathrm{L} \mathrm{KH}_{2} \mathrm{PO}_{4}$ buffer $\mathrm{pH} 2.4$ and the flow rate was $0.50 \mathrm{~mL} / \mathrm{min}$; temperature $35{ }^{\circ} \mathrm{C}$; UV detection $(\lambda=245 \mathrm{~nm}$ ). Legend: meta-phosphoric acid - MPA (3.704 min), ascorbic acid - AA (6.056 min), and uric acid - UA (8.463 min).

by partial penetration into the pores [28]. In our study, MPA that is ionized at the $\mathrm{pH}$ of the mobile phase is excluded from the ionic functional group $-\mathrm{SO}_{3}^{-}$in the column, reducing its retention time and allowing a better separation from AA and UA that are protonated at the mobile phase $\mathrm{pH}$. The column stability at the very low mobile phase $\mathrm{pH}$ is assured by the polymeric matrix of the stationary phase. In addition, this AA and UA plasma separation method has the advantage of saving time and volume of mobile phase that are of crucial importance for routine analysis. Under these elution conditions, all the peaks of interest were well separated and there were no other interfering peaks from the plasma.

\section{Method validation}

The validating parameters for both calibration curves (slope, intercept, correlation coefficient) as well as for the linear range are shown in Table 1. Results indicated an excellent linearity for both analytes over the referred concentration ranges with correlation coefficients $\left(r^{2}\right) \geq 0.999$. The LOD of the assay (at a signal-to-noise ratio of 3) for AA and UA was 1.02 and $1.42 \mathrm{nmol} / \mathrm{mL}$, respectively, while the LOQ (a signal-to-noise ratio of 10) ranged from 0.306 to $0.426 \mathrm{nmol} / \mathrm{mL}$. The precision of isocratic HPLC-UV methodology was evaluated by performing intra- and inter-day multiple injections of AA and UA standard solutions with three different concentrations and by checking the percentages of coefficient of variation of the peak area. The results presented in Table 2 revealed a great repeatability for both antioxidants, since the CV (\%)

\section{Table 1}

The regression equations, the linear range and the limits of detection and quantification of plasma ascorbic acid (AA) and uric acid (UA).

\begin{tabular}{llllll}
\hline Analytes & $\begin{array}{l}\text { Linear range } \\
(\mu \mathrm{mol} / \mathrm{L})\end{array}$ & Linear equation & $\mathrm{r}^{2 \mathrm{a}}$ & $\begin{array}{l}\mathrm{LOD}^{\mathrm{b}} \\
(\mathrm{nmol} / \mathrm{mL})\end{array}$ & $\begin{array}{l}\mathrm{LOQ}^{\mathrm{c}} \\
(\mathrm{nmol} / \mathrm{mL})\end{array}$ \\
\hline $\mathrm{AA}$ & $5-200$ & $\mathrm{y}=20.822 \mathrm{x}-14.629$ & 0.999 & 0.306 & 1.02 \\
$\mathrm{UA}$ & $10-500$ & $\mathrm{y}=0.6052 \mathrm{x}-0.6193$ & 0.999 & 0.426 & 1.42 \\
\hline a & $\mathrm{r}^{2}-$ correlation coefficient. & & & \\
b & LOD - limit of detection. & & \\
c & LOQ - limit of quantification.
\end{tabular}

values for intra-day were lower than $1.8 \%$ and under $6.5 \%$ for the inter-day. The assessment of the analytical recovery was based on the difference between the total concentration determined in the spiked plasma samples and the concentration in the non-spiked samples (Table 3). Three different known amounts of AA and UA authentic standards were added to the plasma samples $(n=3)$ which were subjected to the chromatographic analysis. Table 3 shows the good recovery for both antioxidants. For AA the recovery ranged from $92 \%$ to $96 \%$ and for UA from $99 \%$ to $100 \%$. Regarding the validation parameters we cannot compare our results with others reported in literature. The few published results for the simultaneous determination of AA and UA plasma levels used different separation methods (capillary electrophoresis and RP-HPLC-ECD) $[16,18]$. Our methodology shows that it is possible to accurately determine the amount of AA and UA in plasma samples by HPLC with UV detection, which does not agree with Li and Franke [16] who reported that HPLC-UV is not suitable for plasma AA determination.

\section{Application of the method}

The presented methodology was employed for the assessment of AA and UA levels in 321 plasma samples from subjects with no declared chronic diseases. The mean values for the concentrations of

Table 2

Intra- and inter-day $(n=10)$ precision data for peak area (mean $\pm S D)$, and coefficient of variation (CV) of three different concentrations of ascorbic (AA) and uric (UA) acids.

\begin{tabular}{|c|c|c|c|c|c|}
\hline \multirow[t]{2}{*}{ Analytes } & \multirow{2}{*}{$\begin{array}{l}\text { Standard } \\
\text { concentration } \\
(\mu \mathrm{mol} / \mathrm{L})\end{array}$} & \multicolumn{2}{|l|}{$\begin{array}{l}\text { Intra-day precision } \\
(\mathrm{n}=10)\end{array}$} & \multicolumn{2}{|l|}{$\begin{array}{l}\text { Inter-day precision } \\
(n=10)\end{array}$} \\
\hline & & Mean \pm SD & $\begin{array}{l}\mathrm{CV} \\
(\%)^{\mathrm{a}}\end{array}$ & Mean \pm SD & $\begin{array}{l}\mathrm{CV} \\
(\%)^{\mathrm{a}}\end{array}$ \\
\hline \multirow[t]{3}{*}{ AA } & 15 & $293.029 \pm 3.94$ & 1.34 & $304.152 \pm 13.76$ & 4.52 \\
\hline & 25 & $496.689 \pm 0.44$ & 0.09 & $521.579 \pm 28.74$ & 5.51 \\
\hline & 75 & $1520.214 \pm 0.63$ & 0.04 & $1508.263 \pm 14.20$ & 0.94 \\
\hline \multirow[t]{3}{*}{ UA } & 30 & $372.229 \pm 0.32$ & 0.09 & $371.882 \pm 9.41$ & 2.53 \\
\hline & 60 & $770.541 \pm 5.27$ & 0.68 & $776.683 \pm 18.86$ & 2.43 \\
\hline & 200 & $2580.655 \pm 45.79$ & 1.77 & $2446.316 \pm 158.82$ & 6.49 \\
\hline
\end{tabular}

${ }^{\mathrm{a}} \mathrm{CV}(\%)=(\mathrm{SD} /$ Mean $) \times 100$. 
Table 3

Recovery of ascorbic acid (AA) and uric acid (UA) from human plasma samples $(n=3)$.

\begin{tabular}{llrcrl}
\hline \multirow{2}{*}{ Analytes } & \multicolumn{2}{l}{ Concentration $(\mu \mathrm{mol} / \mathrm{L})$} & \multirow{2}{*}{ Recovery $(\%)$} & CV $(\%)$ \\
\cline { 2 - 4 } & Plasma & Spiked & Measured & & \\
\hline AA & $34.2 \pm 6.9$ & 15 & $45.3 \pm 6.4$ & $92 \pm 0.6$ & 0.62 \\
& & 25 & $56.8 \pm 5.5$ & $96 \pm 2.8$ & 2.96 \\
& & 50 & $80.0 \pm 6.2$ & $95 \pm 0.8$ & 0.85 \\
UA & $137.3 \pm 26.7$ & 30 & $167.4 \pm 25.5$ & $100 \pm 1.1$ & 1.10 \\
& & 60 & $196.8 \pm 23.4$ & $100 \pm 1.7$ & 1.70 \\
& & 120 & $254.0 \pm 23.3$ & $99 \pm 1.5$ & 1.51 \\
\hline
\end{tabular}

Table 4

Ascorbic (AA) and uric (UA) acids plasma levels in the apparently healthy subjects, according to gender.

\begin{tabular}{|c|c|c|c|}
\hline \multirow[t]{2}{*}{ Antioxidants $(\mu \mathrm{mol} / \mathrm{L})$} & All $^{\mathrm{a}}$ & Women $^{\mathrm{a}}$ & Men $^{\mathrm{a}}$ \\
\hline & $(321)$ & (187) & (134) \\
\hline $\mathrm{AA}$ & $53 \pm 23$ & $56 \pm 23$ & $48 \pm 23^{\text {*** }}$ \\
\hline UA & $209 \pm 89$ & $171 \pm 65$ & $259 \pm 93^{* * *}$ \\
\hline
\end{tabular}

${ }^{a}$ Values are mean \pm SD for $(\mathrm{n})$ subjects; asterisks denote significant differences between gender.

*** $P<0.001$

AA and UA are illustrated in Table 4. The revealed values for both antioxidants are within the reference range as compared with reported results in literature [30,31]. AA concentrations were significantly higher (17\%) in women than in men $(P<0.001)$, whereas UA levels were significantly higher $(51 \%)$ in men as compared to women $(P<0.001)$.

\section{Conclusion}

The HEMA-BIO 1000 SB analytical column showed the ability to separate AA and UA from MPA with superior resolution as compared with the reversed phase $\mathrm{C} 18$ column. A validated and rapid isocratic HPLC-UV method was successfully developed for the simultaneous determination of AA and UA levels in human plasma. The methodology offers great sensitivity, precision, accuracy and reproducibility for the determination of both antioxidants within $10 \mathrm{~min}$, and is well suited to routine measurements and/or high-throughput clinical analysis.

\section{Acknowledgments}

This work was supported by the project 'Search for nuclear and mitochondrial biomarkers of atherosclerosis in isolated populations from Azores Islands' with a reference M2.1.2/F/009/2007, funded by the Regional Government of the Azores, and R.F. is a PhD grantee of Fundação para a Ciência e a Tecnologia [SFRH/BD/34322/2007].

\section{References}

[1] Lusis AJ. Atherosclerosis. Nature 2000;407:233-41.

[2] Singh U, Jialal I. Oxidative stress and atherosclerosis. Pathophysiology 2006;13: $129-42$.
[3] Jialal I, Devaraj S. Low-density lipoprotein oxidation, antioxidants, and atherosclerosis: a clinical biochemistry perspective. Clin Chem 1996;42:498-506.

[4] Epstein FH, Diaz MN, Frei B, Vita JA, Keaney Jr JF. Antioxidants and atherosclerotic heart disease. N Engl J Med 1997;337:408-16.

[5] Violi F, Micheletta F, Iuliano L. Antioxidants and atherosclerosis. Eur Heart J Supplements 2002;4:B17-.

[6] Levine M, Rumsey SC, Daruwala R, Park JB, Wang Y. Criteria and recommendations for vitamin C intake. JAMA 1999;281:1415-23.

[7] Verrax J, Buc Calderon P. The controversial place of vitamin C in cancer treatment. Biochem Pharmacol 2008;76:1644-52.

[8] Padayatty SJ, Levine M. New insights into the physiology and pharmacology of vitamin C. Can Med Assoc J 2001;164:353-5.

[9] Li Y, Schellhorn HE. New developments and novel therapeutic perspectives for vitamin C. J Nutr 2007;137:2171-84

[10] Frikke-Schmidt H, Lykkesfeldt J. Role of marginal vitamin C deficiency in atherogenesis: in vivo models and clinical studies. Basic Clin Pharmacol Toxicol 2009;104:419-33.

[11] Kim KM, Henderson GN, Ouyang X, et al. A sensitive and specific liquid chromatography-tandem mass spectrometry method for the determination of intracellular and extracellular uric acid. J Chromatogr B 2009;877:2032-8.

[12] Strazzullo P, Puig JG. Uric acid and oxidative stress: relative impact on cardiovascular risk. Nutr Metab Cardiovasc Dis 2007;17:409-14.

[13] Glantzounis G, Tsimoyiannis E, Kappas A, Galaris D. Uric acid and oxidative stress. Curr Pharm Des 2005;11:4145-51.

[14] Wu X, Muzny DM, Chi Lee C, Thomas Caskey C. Two independent mutational events in the loss of urate oxidase during hominoid evolution. J Mol Evol 1992;34:78-84.

[15] Kand'ár R, Žáková P, Mužáková V. Monitoring of antioxidant properties of uric acid in humans for a consideration measuring of levels of allantoin in plasma by liquid chromatography. Clin Chim Acta 2006;365:249-56.

[16] Li X, Franke AA. Fast HPLC-ECD analysis of ascorbic acid, dehydroascorbic acid and uric acid. J Chromatogr B 2009;877:853-6.

[17] Pappa-Louisi A, Pascalidou S. Optimal conditions for the simultaneous ion-pairing HPLC determination ofl-ascorbic, dehydro-L-ascorbic, D-ascorbic, and uric acids with on-line ultraviolet absorbance and electrochemical detection. Anal Biochem 1998;263:176-82.

[18] Zinellu A, Sotgia S, Deiana L, Carru C. Pre-analytical factors affecting ascorbic and uric acid quantification in human plasma. J Biochem Biophys Methods 2006;67: 95-105.

[19] Yao X, Wang Y, Chen G. Simultaneous determination of aminothiols, ascorbic acid and uric acid in biological samples by capillary electrophoresis with electrochemical detection. Biomed Chromatogr 2007;21:520-6.

[20] Dhariwal K, Hartzell W, Levine M. Ascorbic acid and dehydroascorbic acid measurements in human plasma and serum. Am J Clin Nutr 1991;54:712-6.

[21] Karlsen A, Blomhoff R, Gundersen T. Stability of whole blood and plasma ascorbic acid. Eur J Clin Nutr 2007;61:1233-6.

[22] Lykkesfeldt J. Ascorbate and dehydroascorbic acid as biomarkers of oxidative stress: validity of clinical data depends on vacutainer system used. Nutr Res 2012;32:66-9.

[23] Kafkas E, Koșar M, Türemis N, Bașer K. Analysis of sugars, organic acids and vitamin C contents of blackberry genotypes from Turkey. Food Chem 2006;97:732-6.

[24] Romeu-Nadal M, Castellote A, Gayą A, López-Sabater M. Effect of pasteurisation on ascorbic acid, dehydroascorbic acid, tocopherols and fatty acids in pooled mature human milk. Food Chem 2008;107:434-8.

[25] Karlsen A, Blomhoff R, Gundersen TE. High-throughput analysis of vitamin C in human plasma with the use of HPLC with monolithic column and UV-detection. J Chromatogr B 2005;824:132-8.

[26] Causon R. Validation of chromatographic methods in biomedical analysis viewpoint and discussion. J Chromatogr B Biomed Sci Appl 1997;689:175-80.

[27] Chung WY, Chung JKO, Szeto YT, Tomlinson B, Benzie IFF. Plasma ascorbic acid: measurement, stability and clinical utility revisited. Clin Biochem 2001;34: 623-7.

[28] Nováková L, Solich P, Solichová D. HPLC methods for simultaneous determination of ascorbic and dehydroascorbic acids, TrAC. Trends Anal Chem 2008:27:942-58.

[29] Parviainen M, Nyyssonen K. Ascorbic acid. In: de Leenheer AP, Lambert WE, Van Bocxlaer JF, editors. Modern Chromatographic Analysis of Vitamins. Marcel Dekker. Inc.; 1992

[30] Corti A, Casini AF, Pompella A. Cellular pathways for transport and efflux of ascorbate and dehydroascorbate. Arch Biochem Biophys 2010;500:107-15.

[31] Waring W, Webb D, Maxwell S. Uric acid as a risk factor for cardiovascular disease. QJM 2000;93:707-13. 